\title{
Heterozygous aggrecan variants are associated with short stature and brachydactyly: Description of 16 probands and a review of the literature
}

Lucía Sentchordi-Montané $^{1,2,3}$ (D) | Miriam Aza-Carmona ${ }^{2,3,4}$ | Sara Benito-Sanz ${ }^{2,4}$ | Ana C. Barreda- Bonis ${ }^{3,5}$ | Consuelo Sánchez-Garre ${ }^{6}$ | Pablo Prieto-Matos ${ }^{7}$ | Pablo Ruiz-Ocaña ${ }^{8}$ | Alfonso Lechuga-Sancho ${ }^{8}$ | Atilano Carcavilla-Urquí Inés Mulero-Collantes $^{10}$ | Gabriel A. Martos-Moreno ${ }^{11,12}$ | Angela del Pozo ${ }^{2,4}$ | Elena Vallespín $^{2,4}$ | Amaka Offiah ${ }^{13}$ | Manuel Parrón-Pajares ${ }^{3,14}$ | Isabel Dinis $^{15}$ | Sergio B. Sousa ${ }^{16}$ | Purificación Ros-Pérez ${ }^{17}$ | Isabel González-Casado ${ }^{3,5}$ | Karen E. Heath ${ }^{2,3,4}$

\footnotetext{
${ }^{1}$ Department of Pediatrics, Hospital Universitario Infanta Leonor, Madrid, Spain

${ }^{2}$ Institute of Medical and Molecular Genetics (INGEMM), Hospital Universitario La Paz, Universidad Autonóma de Madrid, IdiPAZ, Madrid, Spain

${ }^{3}$ Skeletal dysplasia Multidisciplinary Unit (UMDE), Hospital Universitario La Paz, Madrid, Spain

${ }^{4}$ CIBERER, ISCIII, Madrid, Spain

${ }^{5}$ Department of Pediatric Endocrinology, Hospital Universitario La Paz, Madrid, Spain

${ }^{6}$ Department of Pediatric Endocrinology, Hospital de Terrassa, Terrassa, Spain

${ }^{7}$ Department of Pediatrics, Instituto de Investigación Biomédica de Salamanca (IBSAL), Hospital Universitario Salamanca, Salamanca, Spain

${ }^{8}$ Department of Pediatrics, Hospital Universitario Puerta del Mar, Cádiz, Spain

${ }^{9}$ Department of Pediatrics, Hospital Virgen de la Salud, Toledo, Spain

${ }^{10}$ Department of Pediatrics, Hospital Universitario Río Hortega, Valladolid, Spain

${ }^{11}$ Department of Endocrinology, Instituto de Investigación Sanitaria La Princesa, Hospital Infantil Universitario Niño Jesús, Universidad Autonóma de Madrid, Madrid, Spain

${ }^{12}$ Department of Pediatrics, Universidad Autónoma de Madrid and CIBEROBN, ISCIII, Madrid, Spain

${ }^{13}$ Department of Oncology and Metabolism, Academic Unit of Child Health, Sheffield Children's NHS Foundation Trust, Sheffield, UK

${ }^{14}$ Department of Pediatric Radiology, Hospital Universitario La Paz, Madrid, Spain

${ }^{15}$ Department of Pediatric Endocrinology, Diabetes and Growth Unit, Hospital Pediátrico, Centro Hospitalar e Universitário de Coimbra, Coimbra, Portugal

${ }^{16}$ Medical Genetics Unit, Hospital Pediátrico, Centro Hospitalar de Coimbra, Coimbra, Portugal

${ }^{17}$ Department of Pediatrics, Hospital Universitario Puerta de Hierro Majadahonda, Madrid, Spain
}

\section{Correspondence}

Karen Heath, Institute of Medical \& Molecular Genetics (INGEMM), Madrid,

Spain.

Email: karen.heath@salud.madrid.org

Funding information

Ministerio de Economía y Competitividad, Grant/Award Number: SAF2012-30871 and SAF2015-66831-R; Fundación SEEP

\section{Summary}

Objective: Mutations in the aggrecan gene (ACAN) have been identified in two autosomal dominant skeletal dysplasias, spondyloepiphyseal dysplasia, Kimberley type (SEDK), and osteochondritis dissecans, as well as in a severe recessive dysplasia, spondyloepimetaphyseal dysplasia, aggrecan type. Next-generation sequencing (NGS) has aided the identification of heterozygous ACAN mutations in individuals with short stature, minor skeletal defects and mild facial dysmorphisms, some of whom have advanced bone age (BA), poor pubertal spurt and early growth cessation as well as precocious osteoarthritis. 
Design and methods: This study involves clinical and genetic characterization of 16 probands with heterozygous ACAN variants, 14 with short stature and mild skeletal defects (group 1) and two with SEDK (group 2). Subsequently, we reviewed the literature to determine the frequency of the different clinical characteristics in ACANpositive individuals.

Results: A total of 16 ACAN variants were located throughout the gene, six pathogenic mutations and 10 variants of unknown significance (VUS). Interestingly, brachydactyly was observed in all probands. Probands from group 1 with a pathogenic mutation tended to be shorter, and $60 \%$ had an advanced BA compared to $0 \%$ in those with a VUS. A higher incidence of coxa valga was observed in individuals with a VUS (37\% vs 0\%). Nevertheless, other features were present at similar frequencies.

Conclusions: ACAN should be considered as a candidate gene in patients with short stature and minor skeletal defects, particularly those with brachydactyly, and in patients with spondyloepiphyseal dysplasia. It is also important to note that advanced BA and osteoarticular complications are not obligatory conditions for aggrecanopathies/aggrecan-associated dysplasias.

KEYWORDS

ACAN, aggrecan, brachydactyly, short stature, skeletal dysplasia

\section{1 | INTRODUCTION}

Longitudinal bone growth occurs at the growth plate as a result of chondrogenesis. It is regulated by a complex network of signals from endocrine and paracrine systems as well as interactions between cellular growth factors and extracellular matrix. Mutations in many of these pathways result in growth delay and/or skeletal defects.

Short stature is one of the most common reasons for referral to a paediatric endocrinologist. Next-generation sequencing (NGS) has permitted the identification of genetic defects in subgroups of short stature individuals, including heterozygous mutations in the aggrecan gene (ACAN).

Aggrecan is a major structural component of the cartilage growth plate. Until recently, ACAN mutations had been observed in a few families with spondyloepiphyseal dysplasia, Kimberley type $\left(\mathrm{SEDK}, \mathrm{MIM}\right.$ 608361) ${ }^{1}$; spondyloepimetaphyseal dysplasia, aggrecan type (SEMD, MIM 612813) ${ }^{2}$; and osteochondritis dissecans (MIM 165800). ${ }^{3}$ More recently, through the implementation of NGS, heterozygous ACAN mutations have been reported in individuals with a milder skeletal dysplasia, presenting with short stature and
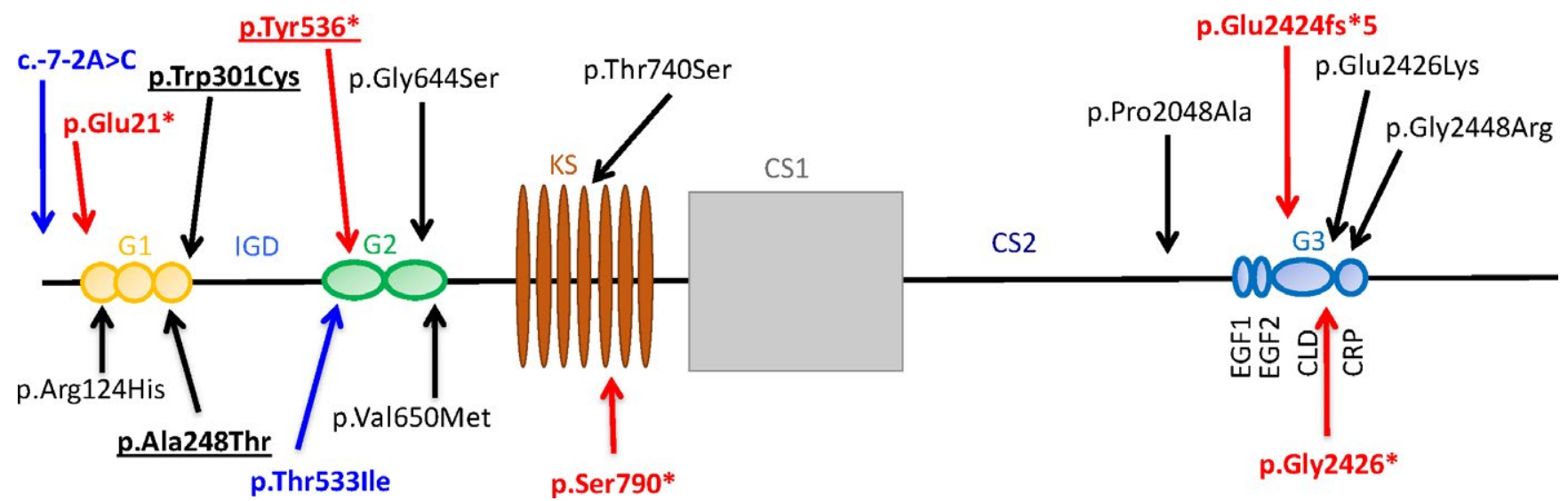

FIGURE 1 Structure of ACAN and the locations of the variants identified in the 16 probands. The G1 region encoded by exons 3-6, the IGD region by exon 7, the G2 region by exons 8-10, the GAG (KS-CS1-CS2) attachment region encoded by exons 11-12, while the G3 region encoded by exons 13-19. Missense variants written in black, while premature truncating (nonsense, frameshift, splicing) mutations written in red. Mutations corresponding to SEDK written in blue. Families with osteoarthritis and/or discopathy underlined [Colour figure can be viewed at wileyonlinelibrary.com] 


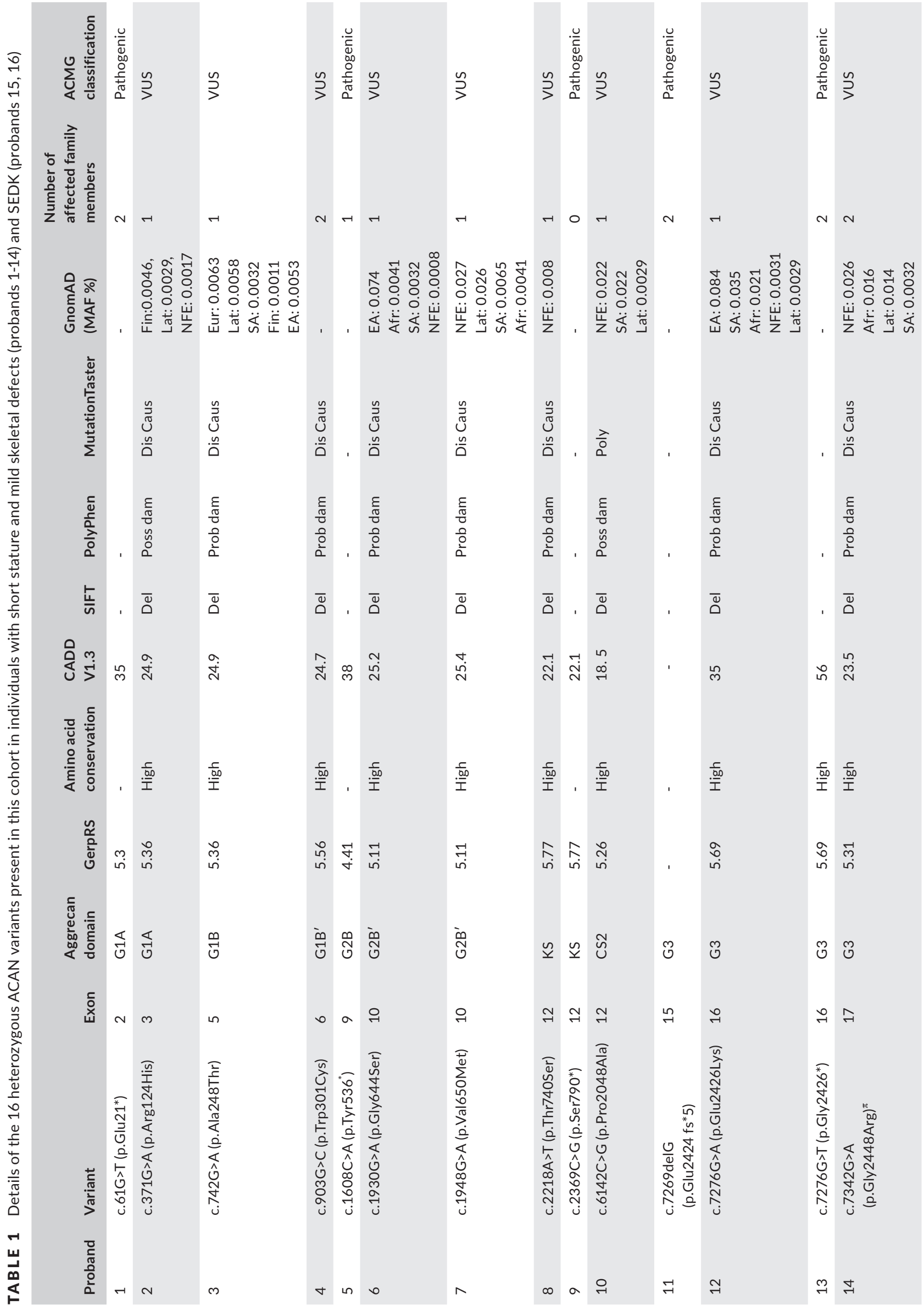




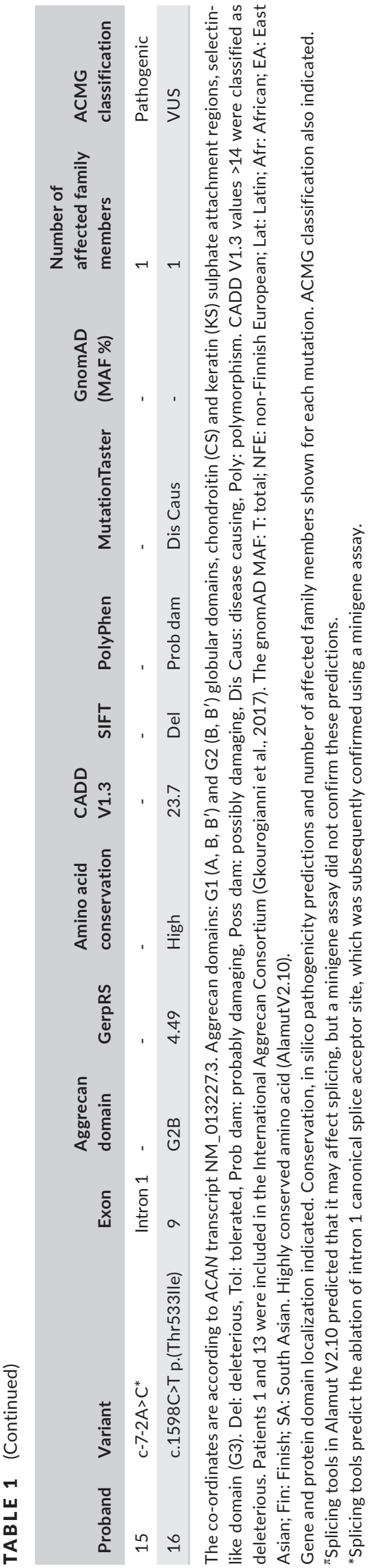

advanced bone age (BA). ${ }^{4-10}$ This led to the creation of an International Aggrecan Consortium for the clinical and genetic evaluation of 103 ACAN heterozygotes from 20 families. ${ }^{6}$ Height appeared to be less affected during childhood (median -2 SDS), and most had advanced BA compared to chronological age (CA).

Aggrecan consists of an N-terminal domain, two globular domains (G1 and G2), two interglobular domains (CS and KS attachment regions), a selectin-like domain (G3) and a C-terminal domain. ${ }^{11}$ Mutations are located throughout the protein, and no genotypephenotype correlations have been observed. ${ }^{6,10}$ The pathogenic mechanisms for the accelerated bone maturation, cartilage degradation and the clinical heterogeneity remain elusive.

We present a retrospective study of the clinical and genetic findings of 16 probands with heterozygous ACAN variants, detected during routine genetic studies using a skeletal dysplasia NGS panel. We also review all cases reported in the literature to determine the frequency of the different clinical characteristics related to aggrecanopathies.

\section{2 | PATIENTS AND METHODS}

All participants provided informed consent for the conducted studies, and the ethical approval was obtained from the Hospital La Paz Ethical Committee.

The 16 probands were referred for molecular study from Spanish and Portuguese endocrinology and genetic clinics. Ten formed part of a cohort of 100 children with short stature and mild skeletal defects in either the proband or one of their parents, in whom SHOX defects had been previously excluded using MLPA (P018G1, MRC Holland) and DNA sequencing. Endocrine disorders including $\mathrm{GH}$ IGF1-related conditions were also excluded by biochemical analysis. The remaining six probands were referred for routine skeletal dysplasia genetic diagnosis ( $\mathrm{n}>1000$ patients). SHOX mutations were similarly excluded in four of these, not conducted in probands 15 16. BA and skeletal surveys were carried out. Blood samples were extracted from the proband and family members, when available.

All probands were analysed using a custom-designed skeletal dysplasia next-generation sequencing (NGS) panel, SKELETALSEQ.V3-6 ( $n=315$-368 genes) and sequenced on a MiSeq/NextSeq sequencer (Illumina, San Diego, CA, USA). Bioinformatic analyses were conducted as previously described. ${ }^{11}$ Conservation, pathogenicity prediction analysis and population frequences of the identified ACAN variants were carried out using CADD V1.3 (http://cadd.gs.washington.edu/), GerpRS (http://mendel.stanford.edu/SidowLab/downloads/gerp/) and Alamut V2.10 (Interactive Biosoftware, France) and gnomAD database (http://gnomad.broadinstitute.org). Variants were subsequently validated by Sanger sequencing as was family testing. Kinship was confirmed using microsatellite marker analysis (Devyser Complete QFPCR, Stockholm, Sweden).

After the identification of an ACAN variant, each referring clinician was asked to complete a specific aggrecanopathy clinical questionnaire including personal and familial records, anthropometric measures, facial dysmorphisms, age of puberty onset and pubertal 
TAB LE 2 Clinical characteristics of probands from group 1 with short stature and mild skeletal defects. The total number presenting each clinical feature is based on paediatric cases $(n=13)$, thus excluding adult patient 14

\begin{tabular}{|c|c|c|c|c|c|c|c|c|c|c|c|c|c|}
\hline & & & & & & Anthrop & netric da & & & Facial dysmorp & isms & & \\
\hline Proband & $\begin{array}{l}\text { Geographical } \\
\text { origin }\end{array}$ & $\begin{array}{l}\text { Mutation cDNA } \\
\text { (protein) }\end{array}$ & $\begin{array}{l}\text { Age } \\
\text { (years) }\end{array}$ & $\begin{array}{l}\text { Gender } \\
\text { (F/M) }\end{array}$ & $\begin{array}{l}\text { SGA } \\
(Y / N)\end{array}$ & $\begin{array}{l}\text { Height } \\
\text { (SDS) }\end{array}$ & $\begin{array}{l}\text { Target } \\
\text { height } \\
\text { (SDS) }\end{array}$ & $\mathrm{SH} / \mathrm{H}$ & BA vs CA & Macrocephaly & $\begin{array}{l}\text { Frontal } \\
\text { bossing }\end{array}$ & $\begin{array}{l}\text { Mid-facial } \\
\text { hypoplasia }\end{array}$ & $\begin{array}{l}\text { Depressed } \\
\text { nasal bridge }\end{array}$ \\
\hline 1 & $\mathrm{Sp}$ & $\begin{array}{l}\text { c.61G>T } \\
(\text { p.Glu21*) }\end{array}$ & 4.5 & $\mathrm{~F}$ & $\mathrm{~N}$ & -3.5 & -3.0 & 0.56 & +1.5 & + & + & + & - \\
\hline 2 & $\mathrm{Sp}$ & $\begin{array}{l}\text { c. } 371 \mathrm{G}>\mathrm{A} \\
\text { (p.Arg124His) }\end{array}$ & 8.0 & $\mathrm{~F}$ & $\mathrm{~N}$ & -3.7 & -2.4 & 0.54 & -2 & - & - & - & - \\
\hline 3 & $\mathrm{Ec}$ & $\begin{array}{l}\text { c.742G>A } \\
\text { (p.Ala248Thr) }\end{array}$ & 14.5 & M & $\mathrm{N}$ & -1.8 & -2.6 & 0.52 & 0 & - & - & - & - \\
\hline 4 & $\mathrm{Sp}$ & $\begin{array}{l}\text { c. } 903 \mathrm{G}>\mathrm{C} \\
\text { (p.Trp301Cys) }\end{array}$ & 7.0 & $\mathrm{~F}$ & $\mathrm{~N}$ & -3.5 & -3.6 & NA & 0 & - & + & + & + \\
\hline 5 & $\mathrm{Sp}$ & $\begin{array}{l}\text { c. } 1608 C>A \\
\left(p . T y r 536^{*}\right)\end{array}$ & 4.5 & $\mathrm{~F}$ & $\mathrm{~N}$ & -3.5 & -3.0 & 0.60 & 0 & - & - & - & - \\
\hline 6 & $\mathrm{Ch}$ & $\begin{array}{l}\text { c.1930G>A } \\
\text { (p.Gly644Ser) }\end{array}$ & 16.0 & $\mathrm{~F}$ & $\mathrm{~N}$ & -2.1 & -2.0 & 0.57 & 0 & - & - & - & - \\
\hline 7 & $\mathrm{Sp}$ & $\begin{array}{l}\text { c.1948G>A } \\
\text { (p.Val650Met) }\end{array}$ & 12.0 & M & $\mathrm{N}$ & -2.6 & -1.4 & 0.52 & -3 & - & - & - & + \\
\hline 8 & $\mathrm{Sp}$ & $\begin{array}{l}\text { c.2218A>T } \\
\text { (p.Thr740Ser) }\end{array}$ & 3.0 & M & $\mathrm{N}$ & -3.2 & NA & 0.57 & 0 & - & + & + & - \\
\hline 9 & $\mathrm{Sp}$ & $\begin{array}{l}\text { c. } 2369 \mathrm{C}>\mathrm{G} \\
(\mathrm{p} . \text { Ser790*) }\end{array}$ & 14.5 & M & $Y$ & -2.2 & -0.6 & 0.52 & +2 & - & + & - & - \\
\hline 10 & $\mathrm{Sp}$ & $\begin{array}{l}\text { c. } 6142 C>G \\
\text { (p.Pro2048Ala) }\end{array}$ & 12.5 & $F$ & $\mathrm{Y}$ & -2.2 & -2.1 & NA & 0 & - & - & - & - \\
\hline 11 & $\mathrm{Sp}$ & $\begin{array}{l}\text { c.7269delG } \\
\text { (p.Glu2424 fs*5) }\end{array}$ & 1.5 & $M$ & $\mathrm{~N}$ & -3.0 & -3.2 & NA & +2 & - & - & - & + \\
\hline 12 & $\mathrm{Sp}$ & $\begin{array}{l}\text { c.7276G>A } \\
\text { (p.Glu2426Lys) }\end{array}$ & 8.5 & $F$ & $Y$ & -2.5 & -1.8 & NA & 0 & - & + & - & + \\
\hline 13 & $\mathrm{Sp}$ & $\begin{array}{l}\text { c. } 7276 G>T \\
(\text { p.Gly2426*) }\end{array}$ & 18.0 & $M$ & $\mathrm{Y}$ & -4.3 & -3.4 & 0.54 & 0 & + & - & - & - \\
\hline \multirow[t]{2}{*}{14} & $\mathrm{Sp}$ & $\begin{array}{l}\text { c. } 7342 \mathrm{G}>\mathrm{A} \\
\text { (p.Gly2448Arg) }\end{array}$ & 46 & $\mathrm{~F}$ & NA & -3.7 & -4.3 & 0.52 & NA & - & + & + & - \\
\hline & & $\begin{array}{l}\text { TOTAL (paediatric } \\
\text { cohort, } n=13 \text { ) }\end{array}$ & $\begin{array}{c}\text { Median } \\
10.2\end{array}$ & $\begin{array}{l}7 \mathrm{~F} \\
6 \mathrm{M}\end{array}$ & 4 & -2.9 & -2.5 & 0.54 & $\begin{array}{l}3 \mathrm{Adv} \\
10 \mathrm{Eq} / \mathrm{Del}\end{array}$ & 2 & 5 & 3 & 4 \\
\hline
\end{tabular}

Geographical origin: Sp, Spain; Ec, Ecuador; Ch, China. Gender: M, male; F, female. SGA: N, no; Y, yes. SH/H, sitting height/height.

$B A$ vs CA.

,$+ \mathrm{BA}>1$ year $\mathrm{CA}$ (advanced).

$0, \mathrm{BA}=\mathrm{CA}$ (equal; between +1 and -1 year).

- , BA $<1$ year CABA (delayed).

NA, Not available.

Facial dysmorphisms and skeletal findings: +, present; -, absent.

spurt and other associated medical conditions, similar to that previously published. ${ }^{6}$ Advanced BA was defined as a BA greater than 1 year compared to the CA, while delayed BA was defined as BA less than 1 year relative to the CA. Brachydactyly was defined as short metacarpals and/or fingers. The clinical data, BA and skeletal surveys were then revised by three experts (LS-M, AO and MP). Subsequently, the 16 probands were divided into two clinical groups: those presenting with short stature and mild skeletal defects (group 1, probands 1-14) and two with SEDK (group 2, probands 15-16).

\section{3 | RESULTS}

\section{1 | Molecular genetics}

A total of 16 heterozygous ACAN variants were identified (Figure 1, Table 1). No other pathogenic mutation or variant of unknown significance (VUS) associated with short stature and skeletal defects, including brachydactyly, was detected in the probands. Six variants were classified as pathogenic mutations (4 nonsense, 


\begin{tabular}{|c|c|c|c|c|c|c|c|c|c|c|c|c|c|}
\hline & & & & & & & Skeletal finding & & & & & & \\
\hline $\begin{array}{l}\text { Broad } \\
\text { nose and } \\
\text { philtrum }\end{array}$ & $\begin{array}{l}\text { Thin } \\
\text { lips }\end{array}$ & $\begin{array}{l}\text { High } \\
\text { arched } \\
\text { palate }\end{array}$ & Hypertelorism & Epicantus & $\begin{array}{l}\text { Triangular } \\
\text { face }\end{array}$ & $\begin{array}{l}\text { Puberty } \\
\text { spurt } \\
\text { (Menarche) }\end{array}$ & Brachydactyly & Hyperlordosis & $\begin{array}{l}\text { Coxa } \\
\text { valga }\end{array}$ & $\begin{array}{l}\text { Other skeletal } \\
\text { findings }\end{array}$ & $\begin{array}{l}\text { Precocious } \\
\text { arthropathy or } \\
\text { discopathy in } \\
\text { family member }\end{array}$ & $\begin{array}{l}\text { Affected } \\
\text { family } \\
\text { members (n) }\end{array}$ & $\begin{array}{l}\text { Affected } \\
\text { family } \\
\text { members } \\
\text { height } \\
\text { (SDS) }\end{array}$ \\
\hline- & - & - & - & - & - & - & + & + & - & - & - & 2 & $\begin{array}{l}-3.0 \\
-1.5\end{array}$ \\
\hline+ & + & + & - & - & - & - & + & + & + & - & - & 1 & -2.7 \\
\hline- & - & - & - & - & - & NA & + & - & + & $\begin{array}{l}\text { Mildly flattened } \\
\text { capital femoral } \\
\text { epiphyses, } \\
\text { slender femora }\end{array}$ & $\begin{array}{l}\text { Osteoarthritis } \\
\text { and discopathy } \\
\text { in mother }\end{array}$ & 1 & -3.0 \\
\hline- & - & - & - & - & - & - & + & - & + & $\begin{array}{l}\text { Slender femora } \\
\text { Osteochondral } \\
\text { knee mild } \\
\text { defects }\end{array}$ & $\begin{array}{l}\text { Familiar } \\
\text { osteochondri- } \\
\text { tis dissecans in } \\
\text { affected father } \\
\text { and uncle }\end{array}$ & 2 & $\begin{array}{l}-4.4 \\
-3.8\end{array}$ \\
\hline - & - & - & - & - & - & - & + & - & - & $\begin{array}{l}\text { Osteochondral } \\
\text { knee mild } \\
\text { defects }\end{array}$ & $\begin{array}{l}\text { Osteoarthritis in } \\
\text { father }\end{array}$ & 1 & -4.5 \\
\hline - & - & - & - & - & - & NA & + & - & - & $\begin{array}{l}\text { Madelung } \\
\text { deformity, } \\
\text { short femoral } \\
\text { necks, mild } \\
\text { epiphyseal } \\
\text { knee defects }\end{array}$ & - & 1 & -3.7 \\
\hline - & + & - & - & + & - & - & + & - & - & - & - & 1 & -2.6 \\
\hline- & - & + & - & - & + & - & + & - & - & - & - & 1 & -3.7 \\
\hline+ & - & - & + & - & - & NA & + & + & - & - & - & - & - \\
\hline- & - & - & - & - & - & NA & + & - & - & - & - & 1 & -2.3 \\
\hline- & - & - & - & - & - & - & + & - & - & - & - & 2 & $\begin{array}{l}-5.8 \\
-3.8\end{array}$ \\
\hline- & - & - & - & - & - & - & + & - & - & $\begin{array}{l}\text { Cone-shaped } \\
\text { epiphysis }\end{array}$ & - & 1 & -1.79 \\
\hline- & - & - & - & - & - & Poor & + & - & - & $\begin{array}{l}\text { Short femoral } \\
\text { neck }\end{array}$ & - & 2 & $\begin{array}{l}-5.0 \\
-3.7\end{array}$ \\
\hline - & - & - & - & - & - & Poor (11y) & + & - & - & - & - & 2 & $\begin{array}{l}-4.3 \\
-3.5\end{array}$ \\
\hline 2 & 2 & 2 & 1 & 1 & 1 & - & 13 & 3 & 3 & 6 & 3 families & 18 & $\begin{array}{l}\text { Median } \\
-3.77\end{array}$ \\
\hline
\end{tabular}

1 frameshift and 1 splicing), while the remaining ten were classified as VUS (Table 1) using the American Society of College of Genetics and Genomics (ACMG) recommendations for classifying variants. $^{12}$

Family testing was carried out in all 16 probands. Mutations were inherited in all but one case (proband 9), which appears to have arisen as a de novo event or due to germinal mosaicism. The variants were identified in a total of 20 family members, 19 adults and one child, all with short stature and/or mild skeletal defects or SEDK (fathers of probands 15 and 16). Unfortunately, further cosegregation studies from multiple generations were not possible.

\section{2 | Clinical group 1 (patients 1-14) with short stature and mild skeletal defects}

Thirteen of the 14 probands were children (age range 1.5-18 years, median 10.2 years). Probands 1 and 13 were previously included in the International Aggregation Consortium study. ${ }^{6}$ Clinical 
characteristics are shown in Table 2. Anthropometric measurements were assessed in the 13 children of group 1. The median height SDS was below average (-2.9), sitting height-to-height ratio was in the normal range (0.54), and BMI was -0.31 SDS. Advanced BA was observed in three probands, while equal or delayed $B A$ with respect to CA was determined in ten. Three probands had reached their final height, two of whom had had a poor pubertal spurt. Examples of growth patterns are shown in Figure S1. Radiological features and hand photographs are shown in Figures S2 and S3, respectively. Brachydactyly (short fingers and/or short metacarpals) was observed in all probands in group 1 . Seven probands (53\%) showed a similar phenotype with frontal bossing, depressed nasal bridge and/ or mid-facial dysplasia (Table 2). Three of the patients (probands 2 , 9 and 12) have recently initiated growth hormone therapy, but no response data are currently available. To determine whether the clinical characteristics were similar or different in individuals with a clearly pathogenic mutation compared to those with a VUS, we made a comparison of the clinical and radiological characteristics of these probands from group 1 (Table 3 ).

\section{3 | Group 2 (probands 15-16)-SEDK}

Heterozygous ACAN mutations were identified in the two probands with moderate skeletal anomalies including platyspondyly, who were subsequently diagnosed as having SEDK (Table 1). Proband 15 was found to have a mutation in the canonical splice acceptor site of intron 1 (c. $-7-2 A>C$ ), which is predicted to result in the removal of exon 2, where the initiation codon is located. We demonstrated, using a minigene assay, that this mutation indeed ablated the intron 1 splice acceptor site, thus confirming the pathogenicity of this variant (Figure S4). The second case, proband 16, has a missense variant (VUS) in ACAN (p.Thr533lle). Clinical and radiological characteristics of both probands are shown in Table 4 and Figure S2, respectively.

\section{DISCUSSION}

A total of 16 heterozygous variants were detected throughout ACAN, 14 in individuals with short stature, mild skeletal defects and/ or facial dysmorphisms (group 1) and two with SEDK (group 2). No other mutation/variant was identified in the skeletal dysplasia patient in the 16 probands, which could explain their phenotype. As functional characterization is not currently feasible for confirming the pathogenicity of the ACAN VUS, we compared the clinical features in probands from group 1 with a pathogenic mutation (nonsense, frameshift, splicing, $n=5$ ) and those with VUS (missense variants, $n=8$ ) (Table 3 ). Individuals with a pathogenic mutation were shorter (median -3.33 vs -2.7 SDS), and $60 \%$ had an advanced BA compared to $0 \%$ in those with a VUS. Advanced BA:CA was only observed in 3/5 individuals with a pathogenic mutation; thus, two individuals had a BA equal or delayed with respect to the CA. To date, a total of 58 probands and 106 family members (total $=164$ heterozygous ACAN-positive individuals with short stature and mild skeletal defects) have been reported in this study and in the literature (Table 5) ${ }^{4-10}$. Although advanced BA is a good indicator for the presence of mutations in ACAN, it cannot be the principal selection criteria. The other major difference was that a third of the individuals with a VUS had coxa valga, whereas no individual with a pathogenic mutation presented with this clinical feature. Nevertheless, other features such as skeletal defects, facial dysmorphisms and precocious arthropathy or discopathy were present at similar frequencies in both variant classification groups. An interesting observation and in contrast to previous data, brachydactyly was observed in all probands.

After analysing the individuals according to the variant classification, we conducted a study of the clinical features of the probands and affected family members from group 1 ( $n=32 ; 14$ children and 18 adults). No sex or ethnic differences were observed. Only $23 \%$ of the children had advanced BA, once again significantly lower than that previously described (Table 5). The degree of short stature was also very variable. Another previously undescribed feature was the presence of mild hip abnormalities in five probands (38\%). Parents of two of these probands suffer with osteoarthritis. Osteoarthritis and disc disease were uncommon in our cohort with only three parents having these medical complications (23\%) (Table 5).

Clinical heterogeneity occurred in some families, as previously reported in a few cases. ${ }^{6,10}$ Proband 3 (p.Ala248Thr-VUS) presents with normal stature although in the lower range (-1.8 SDS), BA is equal to CA but has brachydactyly and minor skeletal defects. He has not yet reached adult height, and early growth cessation occurs in this growth disorder. His mother, with the same variant, presents with short stature (-3 SDS), precocious osteoarthritis and discopathy. Thus, the differences in height and clinical presentation are likely to be associated with age. In a similar way, proband 12 (p.Glu2426Lys- VUS) presents with short stature (-2.5 SDS), BA equal to CA, mild dysmorphic features and skeletal defects. Her father has the same variant but has normal stature although within the lower limit (-1.79 SDS) and only brachydactyly. This clinical heterogeneity is similarly observed in other skeletal dysplasias such as those associated with heterozygous SHOX or NPR2 mutations. ${ }^{13}$

Two heterozygous ACAN variants (1 pathogenic and 1 VUS) were identified in two individuals with SEDK. To date, only one SEDK case with an ACAN mutation in the CS1 domain has been reported in the literature. ${ }^{1}$ Prior to the implementation of NGS, patients with this form of spondyloepiphyseal dysplasia were generally tested for mutations in COL2A1 and, if negative, remained molecularly undiagnosed. Thus, further cases may be identified in the future.

Interestingly, proband 6 presented with Madelung deformity and proband 15 and his father, considered to have SEDK, have curved radii and limited elbow extension. Madelung deformity is typically observed in individuals with Léri-Weill dyschondrosteosis (MIM 127300), isolated or due to post-traumatic conditions. ${ }^{14}$ SHOX defects have been excluded in all probands. This observation is not 

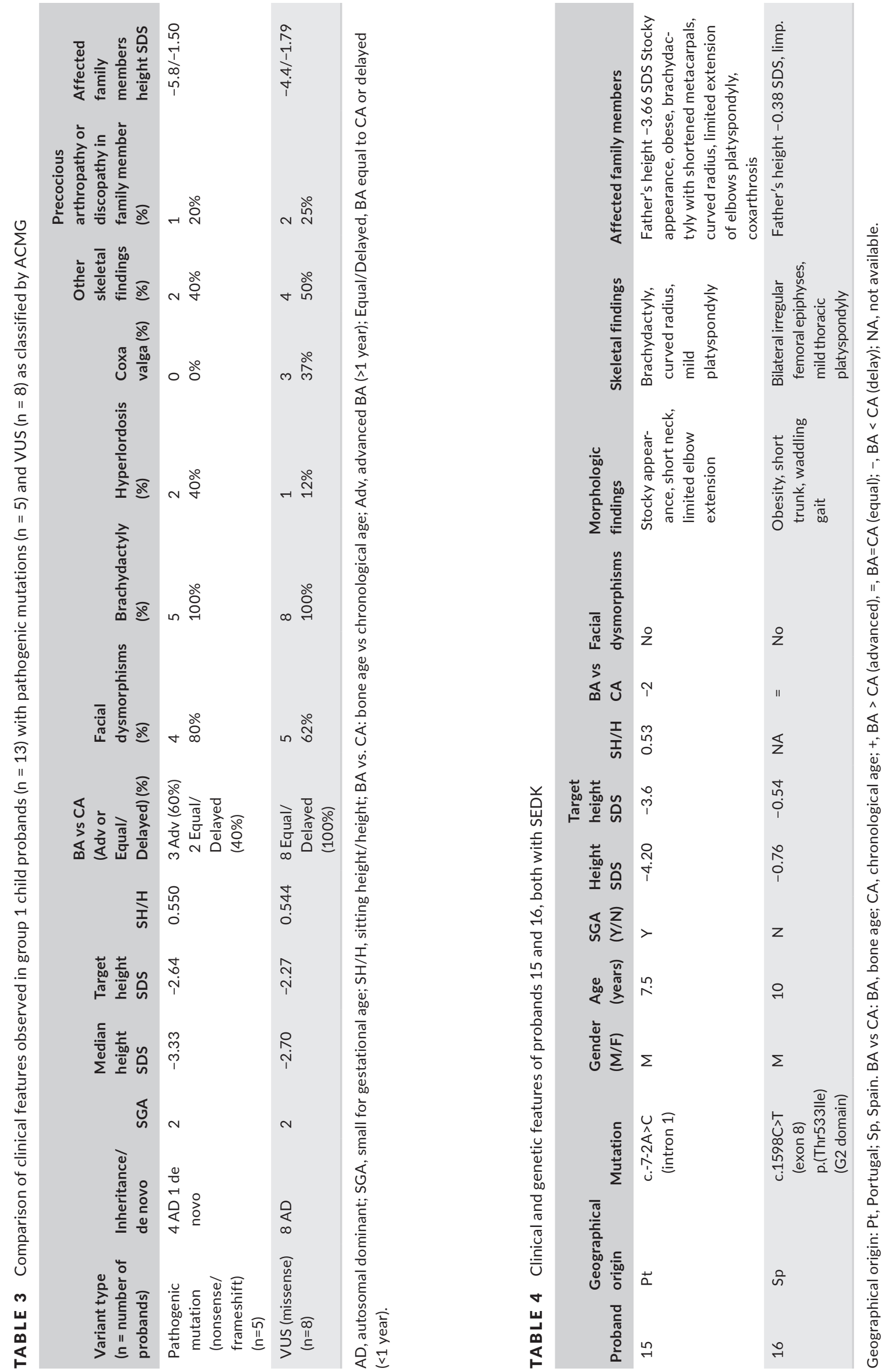


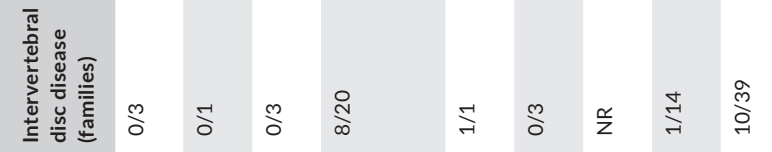

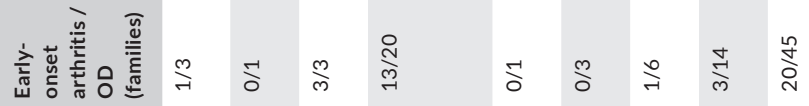

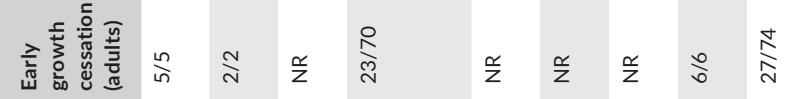

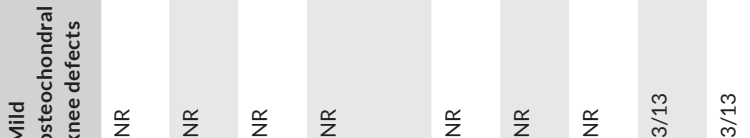

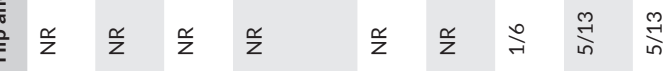

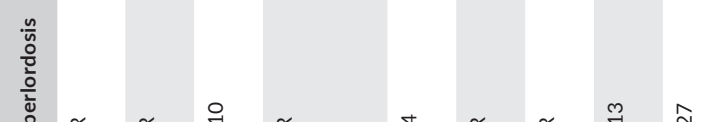

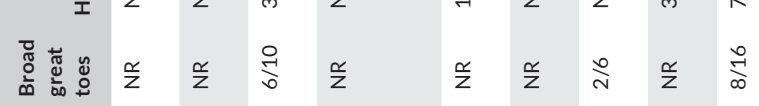

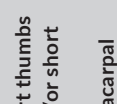

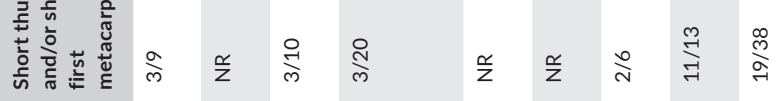

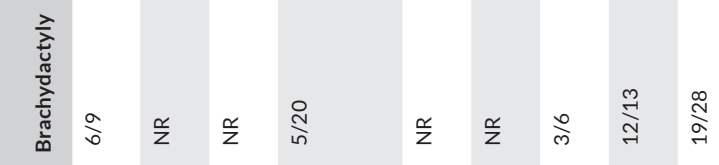

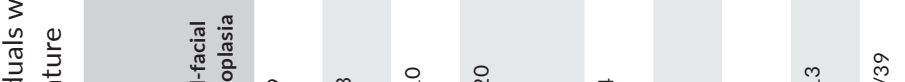

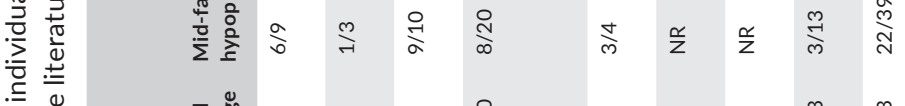

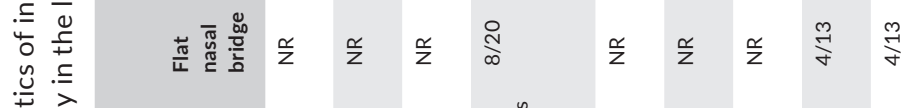

啇

苋 d

㐫

$\frac{\bar{U}}{\sqrt{0}}$

.

$\frac{\bar{c}}{\frac{0}{\pi}}$

交

U.

ह.

言

造

$\frac{0}{0}$

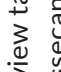

.

ठ

in

山ل

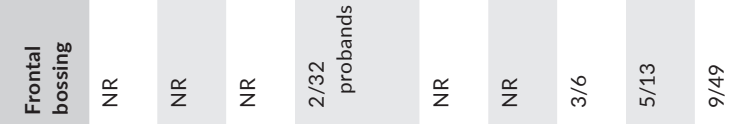

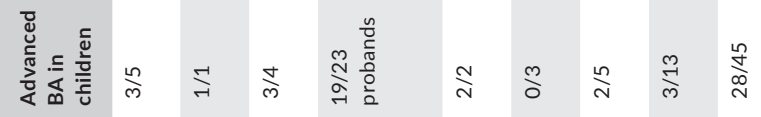

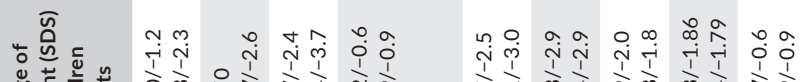

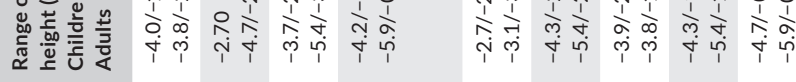

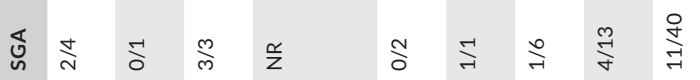

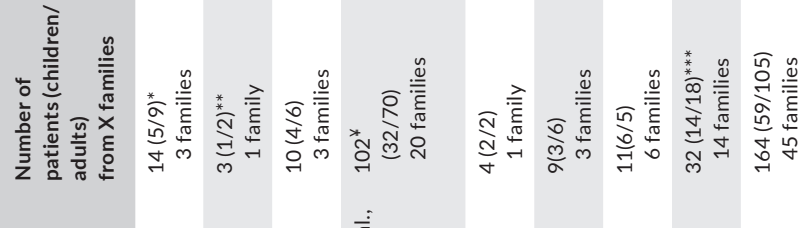

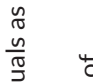

:

苟章

i

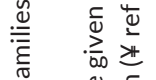

㲾

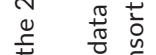

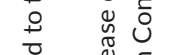

焉

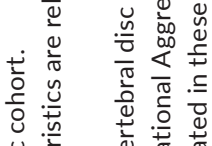

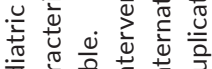

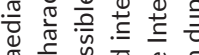

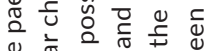

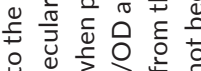

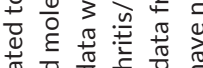

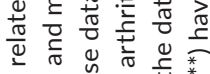

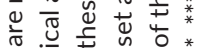

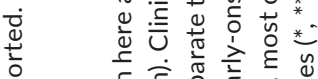

के

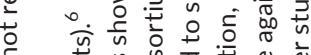

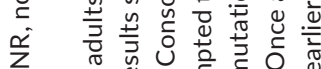

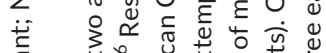

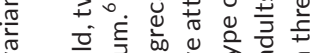

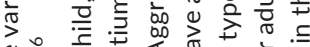

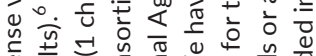

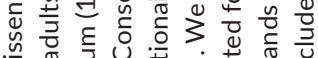
$\bar{\varepsilon} \sigma$ 挥

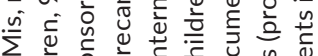

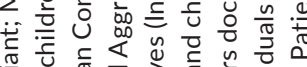

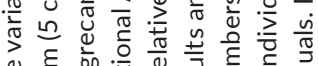

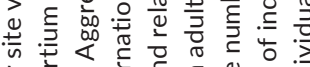
tᄒ

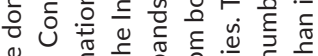

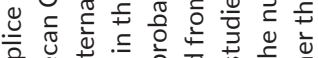

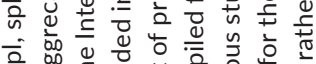

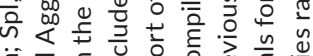

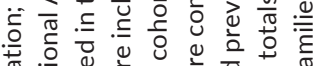

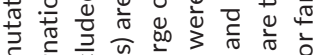

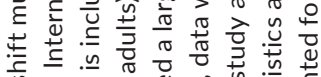

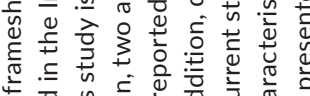
山े

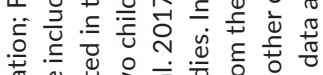

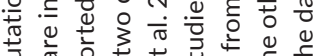

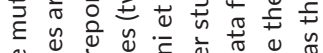

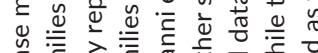

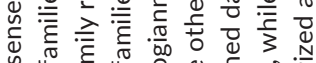

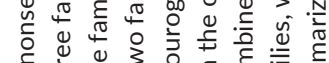

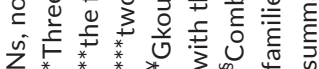


that surprising as SHOX binds to SOX5 and SOX6 which along with SOX9 (SOX trio) activate an aggrecan enhancer, thus participating in common regulatory pathways in chondrogenesis. ${ }^{15}$

The description of our cohort supports the undertaking of a detailed clinical examination and skeletal survey in short stature individuals with suspicion of a mild skeletal dysplasia. Our observation of an association with brachydactyly may help clinicians to request genetic analysis of ACAN.

For now, the diagnosis of this dysplasia is paramount for patients and their families. Individuals with ACAN mutations are at risk of short stature, early growth cessation and poor pubertal spurt, and other health-related problems such as obesity and orthopaedic problems should be prevented or their effects reduced. Careful monitoring of patients with ACAN mutations may help us to identify important genotype-phenotype correlations and to understand their longterm clinical outcomes. Additional familial studies, analysis of larger cohorts, generation of animal models and functional analysis will be also required to determine the incidence of ACAN mutations and the pathogenic mechanism(s). ${ }^{16}$

\section{ACKNOWLEDGEMENTS}

The authors would like to thank the families for their participation in this study. This work was supported in part by the following grants: SAF2012-30871 and SAF2015-66831-R from the MINECO (to K.E.H) and Fundación SEEP (L.S-M and K.E.H). S.B-S was awarded a postdoctoral CIBERER fellowship.

\section{CONFLICT OF INTEREST}

The authors have nothing to disclose.

\section{ORCID}

Lucía Sentchordi-Montané (iD http://orcid.org/0000-0002-4083-3352

Karen E. Heath iD http://orcid.org/0000-0002-5816-7044

\section{REFERENCES}

1. Gleghorn L, Ramesar R, Beighton P, Wallis G. A mutation in the variable repeat region of the aggrecan gene (AGC1) causes a form of spondyloepiphyseal dysplasia associated with severe, premature osteoarthritis. Am J Hum Genet. 2005;77:484-490.

2. Tompson SW, Merriman B, Funari VA, et al. A recessive skeletal dysplasia, SEMD aggrecan type, results from a missense mutation affecting the C-type lectin domain of aggrecan. Am J Hum Genet. 2009;84:72-79.

3. Stattin EL, Wiklund F, Lindblom K, et al. A missense mutation in the aggrecan C-type lectin domain disrupts extracellular matrix interactions and causes dominant familial osteochondritis dissecans. Am J Hum Genet. 2010;86:126-137.
4. Nilsson O, Guo MH, Dunbar N, et al. Short Stature, accelerated bone maturation, and early growth cessation due to heterozygous aggrecan mutations. J Clin Endocrinol Metab. 2014;99: E1510-E1518.

5. Quintos JB, Guo MH, Dauber A. Idiopathic short stature due to novel heterozygous mutation of the aggrecan gene. J Ped Endocrinol Metab. 2015;28:927-932.

6. Gkourogianni A, Andrew M, Tyzinski L, et al. Clinical characterization of patients with autosomal dominant short stature due to aggrecan mutations. J Clin Endocrinol Metab. 2016;102:460-469.

7. Van der Steen M, Pfundt R, Maas SJWH. Bakker-van Waarde WM, Roelof J. Odink RJ, Hokken-Koelega ACS. ACAN gene mutations in short children born SGA and response to Growth Hormone treatment. J Clin Endocrinol Metab. 2017;102:1458-1467.

8. Dateki S, Nakatomi A, Watanabe S, et al. Identification of a novel heterozygous mutation of the aggrecan gene in a family with idiopathic short stature and multiple intervertebral disc herniation. J Hum Genet. 2017;62:717-721.

9. Hu X, Gui B, Su J, et al. Novel pathogenic ACAN variants in nonsyndromic short stature patients. Clin Chim Acta. 2017;469:126-129.

10. Hauer NN, Sticht H, Boppudi S, et al. Genetic screening confirms heterozygous mutations in ACAN as a major cause of idiopathic short stature. Sci Rep. 2017;7:12225.

11. Barraza-García J, Rivera-Pedroza $\mathrm{Cl}$, Hisado-Oliva $\mathrm{A}$, et al. Broadening the phenotypic spectrum of POP1-skeletal dysplasias: Identification of POP1 mutations in a mild and severe skeletal dysplasia. Clin Genet. 2017;92:91-98.

12. Richards S, Aziz N, Bale S, et al. ACMG Laboratory Quality Assurance Committee. Standards and guidelines for the interpretation of sequence variants: A joint consensus recommendation of the American College of Medical Genetics and Genomics and the Association for Molecular Pathology. Genet Med. 2015;17:405-424.

13. Hisado-Oliva A, Garre-Vázquez AL, Santaolalla-Caballero F, et al. Heterozygous NPR2 mutations cause disproportionate short stature, similar to Léri-Weil dyschondrosteosis. J Clin Endocrinol Metab. 2015;100:E1133-E1142.

14. Knutson EJ, Goldfarb CA. Madelung deformity. Hand (N.Y). 2014;9:289-291.

15. Aza-Carmona M, Shears DJ, Yuste-Checa P, et al. SHOX interacts with the chondrogenic transcription factors SOX5 and SOX6 to activate the aggrecan enhancer. Hum Mol Genet. 2011;20:1547-1559.

16. Gibson BG, Briggs MD. The aggrecanopathies: an evolving phenotypic spectrum of human genetic skeletal diseases. Orphanet J Rare Dis. 2016;11:86.

\section{SUPPORTING INFORMATION}

Additional Supporting Information may be found online in the supporting information tab for this article.

How to cite this article: Sentchordi-Montané L, Aza-Carmona $M$, Benito-Sanz S, et al. Heterozygous aggrecan variants are associated with short stature and brachydactyly: Description of 16 probands and a review of the literature. Clin Endocrinol (Oxf.). 2018;88:820-829. https://doi.org/10.1111/cen.13581 